\title{
13 Kaupapa Māori-informed approaches to support data rights and self-determination ${ }^{1}$
}

\author{
Sarah-Jane Paine, Donna Cormack, \\ Papaarangi Reid, Ricci Harris and \\ Bridget Robson
}

\section{Introduction}

Although Indigenous Peoples have always had our own ways of conceptualizing health and well-being and our own systems for preventing illness and for healing, in many colonial nation states Indigenous health is primarily (re)presented through quantitative data and statistics, particularly in narratives of Indigenous health produced by colonial governments. As Walter \& Andersen (2013: 8) note, these data not only (re)produce "knowledge" on Indigenous health, but "have also become the backbone for the creation and implementation of social policy for Indigenous peoples". Quantitative data are used to construct "truths" about Indigenous Peoples, including Māori, and analyzed to produce the "evidence" that is meant to inform health sector policies and interventions (Andersen \& Kukutai 2016; Walter \& Andersen 2013). Quantitative approaches have become relatively dominant in health research in Aotearoa. Within this broader umbrella of quantitative methodologies, the discipline of epidemiology has a powerful presence, often positioned as producing a higher or more reliable "evidence" relative to other methodologies. In this chapter, in line with Walter \& Andersen (2013: $45)$, the term methodology refers to the beliefs about how research can produce knowledge, including what they term the "research standpoint" that involves the researcher's social position, and assumptions about epistemology, axiology and ontology, as well as the particular "theoretical frames" and methods that are used in research. Methods refers to the tools and procedures "for gathering and analyzing information" (Walter \& Andersen 2013: 41).

The assumed superiority of quantitative methodologies in the health sciences in general, and epidemiology specifically, means that research approaches grounded in other ways of knowing are often represented as lesser. This positioning is resisted by Indigenous researchers and scholars (Andersen \& Kukutai 2016), including Māori health researchers (Reid, Cormack \& Paine 2019). Kaupapa Māori research approaches offer methodologies grounded in Māori values, knowledge systems and ontologies (Pihama 2010; Smith 2012a). Kaupapa Māori epidemiology challenges underlying assumptions of prevailing epidemiological methodologies and methods, proposing resistant and alternative ways to think about quantitative data, to formulate research questions, and to undertake research. In addition, Kaupapa 
Māori epidemiology troubles the often-unquestioned assumption that quantitative methodologies, and in the health sciences, epidemiological approaches more particularly, provide the best "evidence" on which to base policies. This chapter presents and discusses examples of approaches developed in Aotearoa, including Mana Whakamārama (Equal Explanatory Power), and age-standardization to an Indigenous standard, and considers the role Kaupapa Māori epidemiology may have in re-visioning quantitative Māori health research methodologies and approaches. The chapter also explores how Kaupapa Māori quantitative approaches can support Māori data rights and Indigenous Data Sovereignty and contribute to broader goals of Indigenous self-determination. Indigenous Data Sovereignty is underpinned by "Indigenous collective rights to data about our peoples, territories, lifeways and natural resources" (Walter \& Suina 2019) and is an expression of inherent Indigenous rights (Kukutai \& Taylor 2016).

\section{Knowledge, power and science}

The (re)presenting of Indigenous Peoples and knowledges as inferior is fundamental to the work of colonialism, and particularly to Westernized imperial approaches to research and "science" (Smith 2012b; Whitt 2009). Rather than an unintended side-effect of colonization, the devaluing and destruction of Indigenous knowledge systems was an active and intentional part of the colonial project (Smith et al. 2016). As Māori ways of knowing were de-centered, Westernized imperialist approaches to knowledge and research were promoted as superior, more credible and more capable of producing "the truth".

Western colonial knowledge systems fixate on drawing boundaries between disciplines and organizing knowledge, and the methodologies related to the (re) production of knowledge, into hierarchies (Smith 2012a). In dominating research approaches in Aotearoa, quantitative and qualitative methodologies are generally positioned as separate, and sometimes in opposition, reflecting the tendency to dichotomization that characterizes "science" in Westernized academic settings. This separation between quantitative and qualitative approaches is in contrast with Indigenous approaches to knowledge that emphasize relationships and the interconnectedness and interdependence of all things, including systems of knowledge (Tsosie 2012). However, the quantitative/qualitative binary has become entrenched in many Westernized academic and research contexts. In addition, quantitative methodologies grounded in positivistic traditions, such as epidemiology, have become dominant in particular disciplines, including medical and health sciences.

When quantitative research is conducted from a positivist position, then it is limited in scope, privileging methods from Europe and ignoring Indigenous knowledges and methodologies. As Indigenous scholars state, positivism's assumption of a singular truth means that "Positivist research methods, therefore, promote epistemicide by oppressing varying worldviews" (Sandoval et al. 2016: 19). This epistemicidal logic is reflected in colonial narratives that discount Indigenous knowledge systems as being archaic and less sophisticated (Whitt 
2009). For Māori, bodies of knowledge surrounding navigation, or the maramataka, for example, integrate diverse and multiple ways of knowing, including systems of counting and measurement (Smith et al. 2016). Coloniality, however, encourages us to stop seeing and imagining ourselves as producers of these kinds of knowledges, supporting the imperial research practices described by Linda Tuhiwai Smith within which Indigenous Peoples were positioned as objects and Indigenous knowledges, when acknowledged, were (re)produced as Western scientific discoveries (Smith 2012b), practices that continue today.

\section{Quantitative research and epidemiology in racialized, colonial contexts}

As noted above, quantitative research occupies a dominating position in health research and in producing knowledge about Māori health. Quantitative health research often draws on epidemiological methodologies and theories to produce and analyze data, to make claims both about the patterning of Māori health and about factors or circumstances that are thought to shape these patterns. Epidemiology has been defined in many ways, including as:

the science and practice which describes and explains disease patterns in populations, and uses this knowledge to prevent and control disease and improve health ... . The central paradigm of epidemiology is to seek differences and similarities ("compare and contrast") in the disease patterns of populations to gain new knowledge. (Bhopal 2016)

However, epidemiology has often been silent on the theoretical assumptions that shape much of the "science and practice" (Bhopal 2016) of the discipline (Krieger \& Zierler 1996), failing to situate epidemiology within its broader historical, social and political context. Nancy Krieger has called for epidemiologists to both consider and be explicit about the theories that shape their methodologies and methods (Krieger 1994, 2011). Definitions of epidemiology as the study of the distribution and determinants of disease frequency and outcomes between populations, for example, often fail to acknowledge fundamental and critical questions of how we understand who counts as a population in the first place, nor how researchers are positioned in relation to the population they are "studying". How we conceptualize populations necessarily influences how we see data about populations and what we say about it. As Krieger (2012: 649) suggests "populations are first and foremost relational beings, not "things." They are active agents, not simply statistical aggregates characterized by distributions". In racialized contexts, concepts of a "population" cannot be understood outside of colonial racial classifications that ordered Indigenous Peoples into hierarchies, yet much epidemiological research fails to engage meaningfully with this context of population data.

The unsafety of epidemiology, as one branch of quantitative methodologies, for Māori and Indigenous Peoples becomes apparent when we trace the history 
of the discipline and contextualize it in terms of its relationship with the eugenics movement and White supremacist thought (Zuberi 2000). Epidemiology draws heavily on statistical practices that were developed to mark non-White people and communities as deficient and deployed to support imperial claims about the (in)humanity of people racialized as inferior (Zuberi 2000). Colonialism wielded quantitative methods and statistics, such as land surveyance, demography and cartography, to dismember Indigenous ways of knowing and our relationships with our lands and communities (Andersen \& Kukutai 2016), whilst at the same time constructing new "truths" about Indigenous Peoples as un-knowing and unscientific (Smith 2012a; Whitt 2009). Statistics and quantitative research then, as other scholars have noted, forms a critical part of the architecture of Whiteness in colonial systems and structures, including in the production and analysis of data in research and policy settings.

While debates and contestations exist within the field of epidemiology (Wemrell et al. 2016), positivist quantitative research methodologies and methods, including epidemiology, generally rest on several powerful ontological and epistemological assumptions. Firstly, quantitative methodologies tend to embrace the idea of objectivity and a presumed separation of body and mind, reinforcing colonial logics that demarcate boundaries between land and people and contemporaneously between people and data. Objectivity, as a value in quantitative research, can be weaponized to create distance and hierarchy within and between populations, furthering the analytic focus on human difference rather than sameness and fostering the notion that we as peoples are separate from the data that we produce or examine. The value placed on notions of objectivity is in contrast to Indigenous relational ways of being and knowing (Blackstock 2009), and encourages researchers to act as if they, their data and their research practices, are unconnected from broader contexts and histories (Cram 1997), or from their underlying theoretical beliefs. However, as BonillaSilva and Zuberi state:

Statistical analysis is connected to an underlying theory. Statistical results, themselves, do not prove anything beyond the numerical relationship between two or more lists of numbers or variables. The connection of these variables in the real world requires a causal theory ... it is irrelevant whether the [researcher] is aware of the theory.

(2008: 9)

A second and closely related claim is that data produced through statistics represent a fixed and discoverable social reality, rather than one that is partial and contingent on the researchers, their worldviews and their methodologies (Walter $\&$ Suina 2019). This claim serves to divert attention away from the racist foundations of particular methodologies and use of quantitative data in the service of colonial logics (Walter \& Andersen 2013), by presenting quantitative research about Māori as simply factual representations of situations whose causes lie in Indigenous minds, bodies and behavior. It reifies positivism's investment in the 
notion of a singular truth, sustaining disregard for multiple coexisting and interrelated knowledges (Whitt 2009).

A third claim is that quantitative data speak for themselves. This claim rests on both the assumption of objectivity that data are separate from us and on the claim to represent a pre-existing, rather than socially constructed, reality. However, as Bonilla-Silva and Zuberi note

Data do not tell us a story. We use data to craft a story that comports with our understanding of the world. If we begin with a racially biased view of the world, then we will end with a racially biased view of what the data have to say.

(2008: 7)

While many quantitative researchers assert that they report only on what the data say, the fundamental questions about what data are included, and how they are analyzed and interpreted, are determined by the researchers (Cram 1997). In our shared history where the role of the researcher has largely been held by non-Indigenous People, this claim also serves to block Indigenous Peoples from speaking back to problematic data as though our lived experiences are irrelevant in the face of objective, quantitative results.

\section{Kaupapa Māori research and Kaupapa Māori epidemiology}

Kaupapa Māori research approaches in the 1980s and 1990s developed as part of broader movements in education and elsewhere to resist the dominance of colonial institutions and structures and reassert Māori rights to self-determination (Bishop 1998; Smith 2012b). Kaupapa Māori takes for granted the legitimacy of Māori ways of being, doing and knowing, is concerned with collective well-being and benefit, and is grounded in commitments to self-determination and transformation (Bishop 1998; Smith 2012a). In relation to research, Bishop states that it "is predicated on the understanding that Māori means of accessing, defining, and protecting knowledge existed before European arrival in New Zealand" (1998: 201). Kaupapa Māori research approaches are explicitly concerned with undertaking research that will benefit Māori communities and center Māori realities (Pihama 2010; Smith 2012a, 2012b).

Within this broader context, the development of Kaupapa Māori quantitative approaches in health responded to key issues of the time. These included movements for recognition of sovereignty, te Tiriti o Waitangi, and land rights, such as the 1975 Land March, the (re)occupation of Takaparawha and the establishment of the Waitangi Tribunal, as well as the anti-racism protests of the 1981 Springbok tour, and Māori women's movements that challenged oppressive systems. Examples of quantitative Māori health research in the 1980s and 1990s also built on a long history of Māori communities documenting and commenting on Māori health. The foundational 1984 Rapuora Survey on the health of Māori women, was carried out by Te Rōpū Wāhine Māori Toko i te Ora Māori 
Women's Welfare League, led by Erihapeti Murchie, and challenged then prevailing approaches to surveys by embedding Kaupapa Māori principles (Murchie 1984). The Hauora series of books on Māori health statistics, the first of which was published in 1980 by Professor Eru Pōmare, also utilized quantitative data to produce statistics documenting Māori health outcomes.

In 1996, Māori health researchers at the first Hui Whakapiripiri at Hongoeka Marae produced the Hongoeka Declaration, a statement that rearticulated Māori rights to control research about Māori health and laid out commitments including to developing and using Kaupapa Māori research approaches (Te Rōpū Rangahau Hauora a Eru Pōmare 1996). An example of a Māori-led health study undertaken in partnership with Māori communities was the "Mauri Mahi, Mauri Ora, Mauri Noho, Mauri Mate: the Health Effects of Unemployment and Redundancy" study (Keefe et al. 1999). The study incorporated epidemiological methods (a retrospective cohort study) and Kaupapa Māori research approaches to explore the health impacts of factory closures on Māori (Keefe et al. 1999) and embodied many of the processes and practices that characterize Kaupapa Māori epidemiology today, including whānau, consultation, whakapapa and reciprocity. Not surprisingly, the project was impactful, not only in terms of scholarship and knowledge production related to the effects of mass unemployment events for Indigenous communities but also in the way that the research enhanced the voices of those directly affected by neoliberal reforms of the 1980s and 1990s. For Māori health researchers attempting to create space for Kaupapa Māori epidemiology in the academy, the paper by Keefe and colleagues (1999) was foundational in the way it positioned Kaupapa Māori approaches to epidemiology as necessary for reducing the risks of scientific colonialism. As they wrote:

Positioning ourselves as insiders is in direct contrast to approaches that insist that the self be submerged so that the social scientist is unbiased and objective (Collins 1991). Instead we make use of and trust our own "personal and cultural biographies as significant sources of knowledge" (Collins 1991). However, this does not mean that we are unable to carry out research ethically, systematically and "scientifically" (Smith 1995). (1999: 13)

Other studies have been undertaken since that time looking at various health issues, including, for example sleep problems (e.g., Paine et al. 2005, 2013), cardiovascular health (Pitama et al. 2011), cesarean sections (Harris et al. 2007), breast cancer (Curtis, Wright \& Wall 2005) and dialysis (Huria et al. 2018). Within a broader international context, the development of Kaupapa Māori epidemiological studies aligns with parallel activities being undertaken by Indigenous scholars and researchers in relation to Indigenous health in Hawai' $i$, and in the nation states currently known as Australia, Canada and the United States (Prussing 2018).

Kaupapa Māori epidemiology in Aotearoa is part of wider activities to uphold Māori rights as tangata whenua in relation to data and research methodologies and methods. Four of these rights are discussed below as examples of how Kaupapa 
Māori epidemiological research can work alongside and support Indigenous Data Sovereignty and broader rights to self-determination.

\section{The right to monitor the Crown}

Māori have the right to monitor the Crown and to evaluate Crown action and inaction ... . As tangata whenua, our duty includes ensuring the wellbeing of all people in our territories, Māori and tauiwi. This necessitates Māori monitoring health, including any disparities in health outcomes between Māori and non-Māori.

(Reid \& Robson 2007: 1)

Kaupapa Māori epidemiology is not simply a "Māori way" of analyzing, describing and explaining patterns and drivers of health or an "equity-lens" through which health data can be filtered. It is a theoretically driven approach to undertaking quantitative health research that utilizes epidemiology as a tool to monitor Crown “action and inaction”. In Kaupapa Māori epidemiology, Māori hold the power to ask questions about and monitor the State's obligations under te Tiriti o Waitangi and in relation to the United Nations Declaration on the Rights of Indigenous Peoples (UNDRIP). Kaupapa Māori epidemiology speaks back to colonial interpretations of Māori health inequities as natural or due to innate problems with Māori communities or culture, and argues for the right to use data and statistics to shift the gaze toward the organization of society, and the role of the health system, including health policy, in creating and sustaining health inequities. Through prioritizing the examination of power relations between individuals, groups and populations within society, Kaupapa Māori-driven epidemiology allows for us to see the patterns of ill-health and disease as a consequence of colonization and the social and political relationships between Māori and the Crown (Keefe et al. 1999). It also encourages this same shift in the development of policy, away from policies that aim to act on Māori individuals or communities, to policies that seek to address the social and structural drivers of health.

The development of Kaupapa Māori epidemiology has not been smooth or without controversy. Indigenous memories of harmful quantitative health research have meant that some communities are hesitant to consider the potential for epidemiology, and other methodologies that are strongly linked to positivistic traditions, to be transformational (as was the original goal of Kaupapa Māori epidemiology), an understandable position in light of how quantitative methods are used to reinforce colonial projects (Smith 2012b). In particular, some of the early work was criticized for the use of a Māori/non-Māori analytical frame, which was viewed as an attempt to measure Māori experiences of health and health care relative to those of the Pākehā majority as though this was a standard we should aspire to (Reid, Robson \& Jones 2000). To the contrary, the use of Māori/nonMāori analyzes acknowledged the fundamental nature of our relationship with the Crown affirmed in te Tiriti o Waitangi and our expectations of good governance and for equity. In Aotearoa, Māori have the right to expect at least the 
same level of health as non-Māori. Therefore, the documentation of inequities in health outcomes, health service utilization and quality of health care exposes the multiple ways in which non-Māori accrue benefit from a health system that they constructed, control and continue to shape. A Māori/non-Māori analysis of health also highlights the way that institutional racism operates within the health system to provide advantage to some groups relative to others.

\section{The right to be counted}

Being counted is an acknowledgement of both existence and value. It means that one matters.

(Te Rōpū Rangahau Hauora a Eru Pōmare 2000)

Epidemiology, as a study of population patterns, has a primary interest in being able to define a population - who is included or not and where the boundaries of belonging are. As noted earlier, epidemiology is fundamentally concerned with measuring (ill)-health within and between populations (Bhopal 2016). However, there are longstanding, and well-documented issues with the (mis)counting of Indigenous populations in relation to health data (e.g., Anderson et al. 2016), including for Māori (e.g., Cormack \& Harris 2009). In addition to issues with the construction of colonial nation-state schema for classifying Indigenous Peoples (Cormack, Reid \& Kukutai 2019), is the fact that many official systems fail to count Indigenous populations consistently or appropriately even by their own standards, flawed though those standards may be. Research in Aotearoa has documented significant under-enumeration of Māori in vital statistics historically, including in birth and death registrations (e.g., Cormack \& Harris 2009; Te Rōpū Rangahau Hauora a Eru Pōmare 2000), as well as in the population census (Kukutai \& Cormack 2018). Health data also continue to undercount Māori in many key datasets, including hospitalizations (Cormack \& Harris 2009; Scott et al. 2018). Given that these datasets tend to be the basis of population numerators and denominators for analysis, implications for quantitative Māori health research are significant

Walter (2018) describes the "paradox" of Indigenous data, whereby there is "too much" of some types of data, and "too little" of other types. Similar to other Indigenous Peoples, data gaps for Māori continue to exist, where data relevant to understanding Māori health and well-being and developing appropriate policy responses, are not available or are incomplete, because data are not collected or are not disaggregated to allow for exploring patterns and outcomes for Māori separately. Policy developed in these contexts will continue to serve settler colonial interests. Part of the work undertaken in Kaupapa Māori epidemiology, then, is to advocate for the right of Māori to be counted in datasets of importance or relevance to us, or that may be important for understanding health for our communities, a shared goal of Indigenous Data Sovereignty. This has included, for example, work to both promote the appropriate collection and use of ethnicity data in key settings, as well as the development of statistical methods to adjust 
for the undercount of ethnicity in current datasets to provide for better estimates (Cormack \& Harris 2009; Robson \& Harris 2007).

\section{The right to have a powerful voice}

Māori have the right to recognition as a people, not a minority group nor a subgroup whose needs are subsumed by those of the total population ... . These rights are pertinent to the design, analysis and reporting of surveys.

(Te Rōpū Rangahau Hauora a Eru Pōmare 2002)

Epidemiological studies and national monitoring surveys that take a total population approach inevitably produce evidence that favors numerically dominant groups in society (Simmonds et al. 2008), creating stories (and policies) that highlight their profile of exposures or access to the social determinants of health whilst at the same time subsuming Indigenous experiences of the health system within those of the total population (Robson \& Reid 2001). In Aotearoa, for example, it is not uncommon to hear claims of success when Māori make up 15\% of a study sample, as though our rights to participate in health research are directly linked to our proportion of the total population. Policies and programs developed from this type of thinking and data are more likely to meet non-Indigenous needs, silencing the existence and extent of inequities and limiting potential for meaningful interventions as they will be unlikely to reflect the needs of those with the greatest risks (Robson \& Reid 2001).

Mana Whakamārama, or equal explanatory power, was an early step toward bringing Māori voices to epidemiology, recognizing Māori statistical needs as having equal status with those of the total population (Te Rōpū Rangahau Hauora a Eru Pōmare 2002). Equal explanatory power foregrounds the importance of having sufficient statistical power to conduct analyzes for Māori to the same depth and breadth as non-Māori, allowing the estimation of population prevalences for Māori and non-Māori populations, whilst at the same time enabling comparisons to be made. Māori epidemiologists argued for the stratification of survey samples by ethnicity in order to explore factors contributing to differences in the prevalence of health outcomes and to enable the comparison of distributions and profiles of "risk factors" by ethnicity. Similarly, stratification by socioeconomic deprivation was also argued to be important not only for understanding the extent to which economic or non-economic consequences of colonization and racism underlie health inequities but also for creating knowledge for action (Krieger 2019).

The expansion of the principles of equal explanatory power from the original cross-sectional national surveys (Mihaere et al. 2009; Paine et al. 2005) to longitudinal cohort studies (Paine et al. 2013) and randomized controlled trials (Selak et al. 2013; Bramley et al. 2005) showcases the level of success that can be achieved when Mana Whakamārama is understood as more than just "tweaking" the way that epidemiologists and biostatisticians approach survey sample design but rather as space for Indigenous knowledges to support excellence and innovation in research design and data practices. 
However, the stratification of samples by ethnicity in and of itself is not enough to mitigate the risks of harmful health research and the critical importance of equal analytical power, described as "the power of definition, explanation and meaning" (Te Rōpū Rangahau Hauora a Eru Pōmare 2002) appears to have been lost or ignored in the way Mana Whakamārama has been taken up in some spaces. Equal analytical power argues that the transformation of health outcomes requires Māori to be involved not only as participants but also as data gatherers, data analyzers, data interpreters and data governors. Although some non-Māori have adopted the principles of equal explanatory power into their study designs, the creation of safe relations between the researchers and participants (Fink et al. 2011) and interpretation of Māori health data as a reflection of our historical and contemporary realities (Reid, Cormack \& Paine 2019) not only requires Indigenous leadership but also a critical scholarship at every step of the research process. Equally important is to challenge the framing of this valid methodological approach to enhance Māori representation in health research as "over-sampling", when the reality is that Western epidemiology has allowed non-Māori to be "over-sampled" and thus over-represented in health research for years (Te Rōpū Rangahau Hauora a Eru Pōmare 2002).

A further example of a Kaupapa Māori response to the right to be represented and heard in research is age-standardization to an Indigenous population. Agestandardization is an epidemiological technique used to compare overall morbidity or mortality rates between groups differing in terms of their age-structures. The choice of standard population is important because in the process of standardizing health data we are emphasizing those events that are more common in the agegroups represented by the standard population. Thus, an older standard population will put more weight on events such as cardiovascular disease (CVD) or cancerrelated deaths, whereas a younger standard population will have greater weight on childhood events.

The choice of standard population matters for Indigenous health. If we choose to use an older standard population, such as the World Health Organization (WHO) standard, then the age-standardized rates produced will more closely reflect non-Indigenous rates and therefore give more weight to the non-Indigenous population experience. The development of an Indigenous standard population, as described by Simmonds and colleagues (2008), was a critique of the assumptions and practices that underpin age-standardization and showed how analytical choices can affect the magnitude of mortality rates, rate ratios and rate differences, the relative ranking of causes of death and the relative width of confidence intervals.

Mana Whakamārama and age-standardization to an Indigenous standard are expressions of self-determination in health research, initially demonstrating how Māori leadership in epidemiology could result in large numbers of Māori respondents in national surveys but also extending to the development of critical epidemiological techniques. Although they were developed to improve and enhance the monitoring of Māori health status and health inequities by the Government, the State continues to demonstrate its dedication to re-creating itself rather than the sovereignty goals that underpin Kaupapa Māori epidemiology. 
For example, recent Ministry of Health reports suggest they have removed equal explanatory power from the design of the NZ Health Survey despite recognizing the importance of these principles for meeting their Treaty obligations (Ministry of Health 2019). Similarly, significant changes to the methodology used for the 2018 Population Census resulted in the lowest Māori response rate in modern times (Kukutai \& Cormack 2018). Despite the availability of proven quantitative research approaches and Indigenous data expertise, it is clear that securing our tangata whenua interests in and rights to good data will require a re-visioning of the role of the State in collecting and analyzing Māori health data, aligning with principles of Māori Data Sovereignty (Te Mana Raraunga 2018).

\section{The right to name racism and colonialism}

The attentiveness to history and context of Kaupapa Māori research supports the right of Māori to name the systems and structures of racism and colonialism that create and maintain White privilege in society, thereby shaping Māori health experiences and outcomes over generations (Keefe et al. 1999). Māori have continued to question the utility of statistics about Māori health that are not contextualized:

Analysis and commentary complement statistics to give a fuller portrayal of Māori health. Statistics alone may show differences in health status, but are of limited use unless there is informed interpretation to highlight causes of differences and to point to remedial action. This volume also draws attention to Māori ill-health being to a great extent as a result of socio-economic and socio-cultural factors which have their roots in colonialism, and the struggle to adapt to rapid change arising from post-World War Two urbanisation. Until the grievances arising from failure to honour the Treaty of Waitangi are resolved, Māori ill-health will remain a problem.

(Murchi E, in Pomare et al. 1995: 14)

Kaupapa Māori epidemiology requires researchers to move from description to explanation and theorization of the processes that are implicated in health outcomes, a call that has been made by other scholars for a more critical epidemiology (e.g., Jones 2001; Krieger 2019). It supports challenges to epidemiology's tendency to regard categories of "race"/ethnicity as risk factors in themselves, rather than as markers of the riskiness of living in colonial, racialized societies (Cormack et al. 2019; Jones 2001; Te Rōpū Rangahau Hauora a Eru Pōmare 2002). As Kaupapa Māori health researchers have stated:

The lack of vigorous exploration of the basis of Māori and non-Māori differences in health data is distancing, othering, and a breach of rights. It indicates a lack of serious intention to properly address disparities and prevents others from taking up that challenge as fully equipped as possible. It is also wasteful.

(Te Rōpū Rangahau Hauora a Eru Pōmare 2002: 17) 


\section{Re-visioning Māori health research: epidemiology, Māori Data Sovereignty and self-determination}

Kaupapa Māori epidemiological methods have pushed health researchers to think more critically about some of the previously taken-for-granted practices and conventions in epidemiology, including the definition, collection and use of ethnicity data, approaches to recruitment and sampling, statistical techniques such as agestandardization and stratification, and perhaps more fundamentally, the nature of relationships between "researchers" and the "researched", the positionality of the researchers and the theoretical underpinnings of epidemiology as a "science". Indigenous scholars Andersen \& Kukutai state that the:

defining characteristic of historical quantitative research involving Indigenous individuals and communities is that quantitative researchers engaged in virtually no collaboration with Indigenous peoples with respect to the categories used to organize the information they proposed to collect, the specific questions asked, the communities from which the information was drawn and the eventual interpretations derived from these efforts.

In contrast, Kaupapa Māori epidemiology also offers potential for a more critical, contextualized and compassionate methodology, and a reconfiguration of data relations and data practices within quantitative research. Applying Kaupapa Māori principles and values to epidemiology requires not only a questioning and re-imagining of dominant epidemiological tools and methods, but an opening of the methodology itself. Kaupapa Māori epidemiology can push back against the dis-membering of Indigenous Peoples from data "about" us, by an attentiveness to history and context, but also through an expectation that Kaupapa Māori epidemiology is done "by us, for us", with Māori at the center. In this way, Kaupapa Māori epidemiology is in alignment with principles and goals of Indigenous Data Sovereignty, and is more likely to lead to policies that turn away from reductive, deficit models to support broader goals of Indigenous self-determination

However, the reach of Kaupapa Māori epidemiology into the Westernized institutions that fund and produce the majority of quantitative health research in Aotearoa is limited. Much quantitative health research remains tightly and narrowly focused on description - that is, pointing out where ethnic inequities exist between populations - with relatively few studies (or researchers) prepared to reveal and confront the ways in which power and privilege are linked to their existence. It is this research that often shapes the types of policy responses and interventions that are prioritized or championed. Maggie Walter's important observations about 5D data that focuses on Indigenous difference, disparity, disadvantage, dysfunction and deprivation (Walter 2018) remind us that Kaupapa Māori epidemiological techniques, in their own right, are not decolonizing. Knowing how to design studies to incorporate equal explanatory power for Māori, for example, or to age-standardize rates to an Indigenous standard 
are not sufficient to achieve Māori rights to health equity or self-determination. Transformation will require a laying bare of epidemiological thinking through deeper understanding of the ways the discipline has contributed to the disempowerment of Indigenous Peoples.

It remains important to think about the ways in which Kaupapa Māori epidemiology challenges the discourse of the "deficit Indigene" (Walter \& Andersen 2013). In recent years, there has been a re-focusing on strengths-based analysis when reporting on Māori health as though studies that seek to uncover stories of resilience and flourishing, even when led by non-Māori researchers, are necessarily safer, more ethical, and therefore preferred. Indigenous refusal to be part of what Tuck (2009) describes as "damage-centered" research is both valid and important when we remember the ways in which quantitative research methodologies have been used to document and display stories of "pain" and "damage" (Tuck 2009) without any intention of using these data to re-create a vision of health that is grounded in rangatiratanga. However, we contend that the full expression of our sovereignty will not be achieved through resilience frameworks, as by definition they are concerned with identifying the factors and behaviors that enable individuals and communities to survive in the face of ongoing coloniality and structural violence. When we limit our vision for Indigenous health to a resilience-based analysis we risk buying into the colonial binary of "good" and "bad" Māori and invisibilizing the way in which interlocking systems of oppression operate to structure the lives of Indigenous People over generations. Smith and Smith assert that "It is important to have a nuanced, theorized, and accurate understanding of what has gone wrong in order to develop more effective transforming responses" (2018: 4). The balance is to achieve this understanding without producing the types of discourses of "pain" and "damage" Tuck (2009) refers to, while allowing for a centering of Indigenous futures and aspirations outside of resilience models of thinking.

In considering how epidemiology can support Indigenous Data Sovereignty and Māori self-determination, we cannot ignore the ways in which statistics and epidemiology contribute to the suppression of Indigenous ways of being and knowing and marginalization of our communities, and often shape much of the policy that has everyday impacts for Indigenous Peoples' lives. The rhetoric of epidemiological studies as aligned with social justice and human rights can hide the coloniality that remains embedded within much epidemiological practice. An interest in ethnic health inequities can feed into the colonial obsession with marking those that are different and then using this to assert control over the lives of those deemed as "others". To decolonize epidemiology we will need to "de-link" (Mignolo 2007) this quantitative research approach from its origins in eugenics and White supremacy, and from its links to capitalism and other co-constitutive systems of oppression, and create alternatives that foreground Indigenous epistemologies.

\section{Conclusions}

Within the current context of local and global movements of Indigenous Data Sovereignty, as Indigenous researchers and communities are considering how we 
can exercise greater control over Indigenous data, disrupt harmful data practices and (re)establish good data relations, it is timely to consider the role of Kaupapa Māori epidemiology and its relationship to policy-making. In Aotearoa, Kaupapa Māori epidemiology developed in response to the silencing of Māori priorities and expectations within research and the policy process. Kaupapa Māori epidemiology was a reclamation of power and an affirmation of Māori rights to produce knowledge that we knew was required for the development of good health policy, and for the purpose of achieving rangatiratanga for Māori. We acknowledge the troubled nature of State policy development and implementation in colonial contexts (Kukutai \& Cormack, this book). However, health policy that is informed by Kaupapa Māori methodologies has greater potential to be transformational for Māori communities than the status quo.

While Kaupapa Māori epidemiology can provide counter-discourses that are contextualized and connected to broader goals of transformation and can provide tools to explore particular research questions, we recognize there is also the potential for our engagement with epidemiology to reify its problematic assumptions and its dominance in health research. Yet, Kaupapa Māori epidemiology can also be understood as an act of resistance, that speaks back to harmful quantitative methodologies, and to the dismissal of multiple ways of knowing and coming to knowledge. Kaupapa Māori epidemiology remains committed to the importance of visioning our Indigenous humanity in health research and seeks to re-humanize data and data practices, by reminding us of our interconnectedness with data and that data are shadows of us and represent people and all our relations. The goal of Kaupapa Māori epidemiology, in line with Indigenous Data Sovereignty, is to realize self-determination that will allow us to move away from the often necessary work of reacting and responding to try to minimize data and research harms for Indigenous people, to re-collect our histories as scientists, knowledge creators and policy-makers and to use these memories to undertake epidemiology for ourselves and for the purpose of supporting healthy, (re)established knowledge systems and research practices focused on Indigenous well-being and futures.

\section{Note}

1 We would like to acknowledge the conversations and collective theorising and action that has happened with past and current colleagues and friends at Te Rōpu Rangahau Hauora a Eru Pōmare that has influenced our thinking and writing in this chapter. Tēnei te mihi nui ki a koutou katoa.

\section{References}

Andersen, C., \& Kukutai, T. (2016). Reclaiming the statistical "native": quantitative historical research beyond the pale. In C. Andersen, \& J. O'Brien (eds.), Sources and Methods in Indigenous Studies (pp. 55-62). New York, NY: Routledge.

Anderson, I., Robson, B., Connolly, M., Al-Yaman, F., Bjertness, E., King, A., et al. (2016). Indigenous and tribal peoples' health (the Lancet-Lowitja Institute global Collaboration): a population study. Lancet, 388(10040), $131 \mathrm{e} 57$. 
Bhopal, R. (2016). Concepts of Epidemiology: Integrating the Ideas, Theories, Principles, and Methods of Epidemiology. Oxford: Oxford University Press.

Bishop, R. (1998). Freeing ourselves from neo-colonial domination in research: a Māori approach to creating knowledge. International Journal of Qualitative Studies in Education, 11(2), 199-219.

Blackstock, C. (2009). First nations children count: enveloping quantitative research in an indigenous envelope. First Peoples Child \& Family Review, 4(2), 135-143.

Bonilla-Silva, E., \& Zuberi, T. (2008). Towards a definition of white logic and white methods. In T. Zuberi, \& E. Bonilla-Silva (eds.), White Logic, White Methods: Racism and Methodology (pp. 3-27). Lanham, MD: Rowman \& Littlefield Publishers.

Bramley, D., Riddell, T., Whittaker, R., Corbett, T., Lin, R.-B., Wills, M., et al. (2005). Smoking cessation using mobile phone text messaging is as effective in Māori as nonMāori. New Zealand Medical Journal, 118, U1494.

Collins, P.H. (1991). Learning from the outsider within. In M. Fonow, \& J.A. Cook (eds.), Beyond Methodology: Feminist Scholarship as Jived Research. Bloomington, IN: Indiana University Press.

Cormack, D., \& Harris, R. (2009). Issues in Monitoring Māori Health and Ethnic Disparities: An Update. Wellington: Te Rōpū Rangahau Hauora a Eru Pōmare.

Cormack, D., Reid, P., \& Kukutai, T. (2019). Indigenous data and health: critical approaches to "race"/ethnicity and Indigenous data governance. Public Health, 172, 116-118.

Cram, F. (1997). Developing partnerships in research: Pākehā researchers and Māori research. SITES, 35, 44-63.

Curtis, E., Wright, C., \& Wall, M. (2005). The epidemiology of breast cancer in Māori women in Aotearoa New Zealand: implications for screening and treatment. New Zealand Medical Journal, 118(1209), U1297.

Fink, J.W., Paine, S.-J., Gander, P.H., Harris, R.B., Purdie, G. (2011). Changing response rates from Māori and non-Māori in sleep health postal surveys. New Zealand Medical Journal, 124(1328), 52-63.

Harris, R., Robson, B., Curtis, E., Purdie, G., Cormack, D., \& Reid, P. (2007). Māori and non-Māori differences in caesarean section rates: a national review. New Zealand Medical Journal, 120(1250), U2444.

Huria, T., Palmer, S., Beckert, L., Williman, J., \& Pitama, S. (2018). Inequity in dialysis related practices and outcomes in Aotearoa/New Zealand: a Kaupapa Māori analysis. International Journal for Equity in Health, 17(1), 27.

Jones, C. (2001). Invited commentary: "race," racism, and the practice of epidemiology. American Journal of Epidemiology, 154(4), 299-304.

Keefe, V., Ormsby, C., Robson, B., Reid, P., Cram, F., \& Purdie, G. (1999). Kaupapa Māori meets retrospective cohort. He Pukenga Korero, 5(1), 12-17.

Krieger, N. (1994). Epidemiology and the web of causation: has anyone seen the spider? Social Science \& Medicine, 39, 887-903.

Krieger, N., \& Zierler, S. (1996). What explains the public's health?: a call for epidemiologic theory. Epidemiology, 7(1), 107-109.

Krieger, N. (2011). Epidemiology and the People's Health: Theory and Context. New York, NY: Oxford University Press.

Krieger, N. (2012). Who and what is a "population"? Historical debates, current controversies, and implications for understanding "population health" and rectifying health inequities. The Milbank Quarterly, 90(4), 634-681.

Krieger, N. (2019). Measures of racism, sexism, heterosexism, and gender binarism for health equity research: from structural injustice to embodied harm-an ecosocial analysis. Annual Review of Public Health, 41(1), 37-62. 
Kukutai, T., \& Taylor, I. (2016). Data sovereignty for indigenous peoples: current practice and future needs. In I. Taylor, \& T. Kukutai (eds.), Indigenous Data Sovereignty: Toward an Agenda (pp. 1-22). Canberra: ANU Press.

Kukutai, T., \& Cormack, D. (2018). Census 2018 and implications for Māori. New Zealand Population Review, 44, 131-151.

Mignolo, W.D. (2007). Delinking: the rhetoric of modernity, the logic of coloniality and the grammar of de-coloniality. Cultural Studies, 21(2-3), 449-514.

Mihaere, K.M., Harris, R., Gander, P.H., Reid, P.M., Purdie, G., Robson, B., \& Neill, A. (2009). Obstructive sleep apnea in New Zealand adults: prevalence and risk factors among Māori and non-Māori. Sleep, 32(7), 949-956.

Ministry of Health. (2019). Methodology Report 2018/19: New Zealand Heath Survey. Wellington: Ministry of Health.

Murchie, E. (1984). Rapuora: Health and Māori Women. Wellington: Māori Women's Welfare League.

Paine, S.-J., Gander, P.H., Harris, R.B., \& Reid, P. (2005). Prevalence and consequences of insomnia in New Zealand: disparities between Māori and non-Māori. Australian and New Zealand Journal of Public Health, 29, 22-28.

Paine, S.-J., Priston, M., Signal, T.L., Sweeney, B., \& Muller, D. (2013). Developing new approaches for the recruitment and retention of indigenous participants in longitudinal research: lessons from E Moe, Māmā: maternal sleep and health in Aotearoa/New Zealand. MAI Journal, 2(2), 121-132.

Pihama, L. (2010). Kaupapa Māori theory: transforming theory in Aotearoa. He Pukenga Kōrero, 9(2), 5-14.

Pitama, S., Wells, J.E., Faatoese, A., Tikao-Mason, K., Robertson, P., Huria, T., et al. (2011). A Kaupapa Māori approach to a community cohort study of heart disease in New Zealand. ANZJPH, 35(3), 249-255.

Pomare, E., Keefe-Ormsby, V., Ormsby, C., Pearce, N., Reid, M.J., Robson, B., \& WateneHaydon, N. (1995). Hauora: Mãori Standards of Health III: A Study of the Years 19701991. Wellington: Te Rōpū Rangahau Hauora a Eru Pōmare.

Prussing, E. (2018). Critical epidemiology in action: research for and by indigenous peoples. SSM-Population Health, 6, 98-106.

Reid, P., Robson, B., \& Jones, C.P. (2000). Disparities in health: common myths and uncommon truths. Pacific Health Dialog, 7(1), 38-47.

Reid, P., \& Robson, B. (2007). Understanding health inequities. In B. Robson, \& R. Harris (eds.), Hauora: Mãori Standards of Health IV. A Study of the Years 2000-2005 (pp. 3-10). Wellington: Te Rōpū Rangahau Hauora a Eru Pōmare.

Reid, P., Cormack, D., \& Paine, S.J. (2019). Colonial histories, racism and health-the experience of Māori and Indigenous peoples. Public Health, 172, 119-124.

Robson, B., \& Reid, M.P. (2001). Ethnicity Matters: Māori Perspectives Paper for the Review of the Measurement of Ethnicity in Official Statistics. Wellington, NZ: Stats NZ.

Robson, B., \& Harris, R. (eds.). (2007). Hauora: Mãori Standards of Health IV. A Study of the Years 2000-2005. Wellington: Te Rōpū Rangahau Hauora a Eru Pōmare.

Sandoval, C.D.M., Lagunas, R.M., Montelongo, L.T., \& Díaz, M.J. (2016). Ancestral knowledge systems: a conceptual framework for decolonizing research in social science. AlterNative: An International Journal of Indigenous Peoples, 12(1), 18-31.

Scott, N., Clark, H., Kool, B., Ameratunga, S., Christey, G., \& Cormack, D. (2018). Audit of ethnicity data in the Waikato Hospital Patient Management System and Trauma Registry: pilot of the Hospital Ethnicity Data Audit Toolkit. New Zealand Medical Journal, 131(1483), 21-29. 
Selak, V., Crengle, S., Elley, C.R., Wadham, A., Harwood, M., Rafter, N., et al. (2013). Recruiting equal numbers of indigenous and non-indigenous participants to a "polypill" randomized trial. International Journal for Equity in Health, 12(44). doi:10.1186/1475-9276-12-44.

Simmonds, S., Robson, B., Cram, F., \& Purdie, G. (2008). Kaupapa Māori epidemiology. Australasian Epidemiologist, 15(1), 2-6.

Smith, G. (2012a). Kaupapa Māori: the dangers of domestication. New Zealand Journal of Educational Studies, 47(2), 10-20.

Smith, L.T. (1995). Re-centering Kaupapa Maori research. Paper presented at Te Matawhanui Conference, Massey University. Massey University, New Zealand: Department of Māori Studies.

Smith, L.T. (2012b). Decolonizing Methodologies: Research and Indigenous Peoples (2nd edition). New York, NY: Zed Books.

Smith, L.T., Maxwell, T.K., Puke, H., \& Temara, P. (2016). Indigenous knowledge, methodology and mayhem: what is the role of methodology in producing indigenous insights? A discussion from Mātauranga Māori. Knowledge Cultures, 4(3), 131-156.

Smith, G.H., \& Smith, L.T. (2018). Doing indigenous work: decolonizing and transforming the academy. In E. McKinley, \& L. Smith (eds.), Handbook of Indigenous Education. Singapore: Springer.

Te Mana Raraunga. (2018). Principles of Māori Data Sovereignty. Retrieved from https:// www.temanararaunga.Māori.nz/.

Te Rōpū Rangahau Hauora a Eru Pōmare. (1996). Hui Whakapiripiri: A Hui to Discuss Strategic Directions for Māori Health Research. Wellington: Te Rōpū Rangahau Hauora a Eru Pōmare.

Te Rōpū Rangahau Hauora a Eru Pōmare. (2000). Ethnicity Matters: Review of the Measurement of Ethnicity in Official Statistics. Māori Perspectives Paper for Consultation. Wellington: Te Rōpū Rangahau Hauora a Eru Pōmare.

Te Rōpū Rangahau Hauora a Eru Pōmare. (2002). Mana Whakamārama-Equal Explanatory Power: Māori and Non-Māori Sample Size in National Health Surveys. Wellington: Public Health Intelligence, Ministry of Health.

Tsosie, R. (2012). Indigenous peoples and epistemic injustice: science, ethics, and human rights. Washington Law Review, 87, 1133.

Tuck, E. (2009). Suspending damage: a letter to communities. Harvard Educational Review, 79, 409-428.

Walter, M., \& Andersen, C. (2013). Indigenous Statistics: A Quantitative Research Methodology. Left Coast Press.

Walter, M. (2018). The voice of Indigenous data: beyond the markers of disadvantage. Griffith Review, 60, 256.

Walter, M., \& Suina, M. (2019). Indigenous data, indigenous methodologies and indigenous data sovereignty. International Journal of Social Research Methodology, 22(3), 233-243.

Wemrell, M., Merlo, J., Mulinari, S., \& Hornborg, A.C. (2016). Contemporary epidemiology: a review of critical discussions within the discipline and a call for further dialogue with social theory. Sociology Compass, 10(2), 153-171.

Whitt, L. (2009). Science, Colonialism, and Indigenous Peoples: The Cultural Politics of Law and Knowledge. Cambridge: Cambridge University Press.

Zuberi, T. (2000). Deracializing social statistics: problems in the quantification of race. The Annals of the American Academy of Political and Social Science, 568(1), 172-185 